\title{
CYBER PUBLIC RELATION DALAM AKUN INSTAGRAM @OFFICIAL.ANTAM PT. ANEKA TAMBANG UNTUK MENGHADAPI REVOLUSI INDUSTRI 4.0
}

\author{
Irma Kusuma Dewi1, Kiayati Yusriyah2 \\ 1,2Ilmu Komunikasi, Fakultas Ilmu Komunikasi, Universitas Gundarma \\ Email: irmhadewi1@gmail.com
}

\begin{abstract}
ABSTRAK
Penelitian ini bertujuan untuk mengetahui bagaimana penggunaan Cyber Public Relation di media sosial PT. Aneka Tambang khususnya dalam instagram @official.antam dalam menghadapi revolusi industri 4.0. Sebagai pondasi penelitian ini menggunakan 7-Cs PR Communications. Penliti hanya mengambil sub fokus dalam Channel, Content, Clarity, Continuity and Consistency. Penelitian ini meggunakan metode penelitian kualitatif deskriptif, teknik yang digunakan dalam pengumpulan data adalah teknik wawancara mendalam, observasi. Informan dalam penelitian ini berjumlah 6 orang yan dipilih dengan menggunakan teknik purposive sampling.Untuk menguji keabsahan data peneliti menggunakan triangulasi data. Hasil penelitian ini adalah Cyber Public Relation pada PT Aneka Tambang di Media Sosial dalam menghadapi Revolusi Industri 4.0 menggunakan instagram @official.antam dengan segementasi khalayak dewasa muda yang banyak menggunakan aplikasi instagram sebagai Channel.Content @official.antam memiliki isi konten berupa informasi mengenai perusahaan baik produk maupun fungsi perusahaan, peringatan hari besar, kegiatan csr, dan informasi seputar pengetahuan umum. Dalam Clarity (Kejelasan) konten instagram antam memiliki kejelasan dalam penyampaian isi konten, Pihak antam menggunakan bahasa yang baku untuk menyampaikan isi pesan. Untuk Continuity and Consistency (Keberlanjutan dan Kosistensi) @official.antam mengunggah kontennya regulary setiap hari. Instagram PT. Aneka Tambang Tbk bertujuan untuk company expose untuk menunjukkan eksistensi perusahaan di media sosial khususnya instagram.
\end{abstract}

Kata Kunci: Cyber Public Relation; Instagram; Revolusi Industri 4.0.

\section{CYBER PUBLIC RELATIONS IN INSTAGRAM ACCOUNT @OFFICIAL.ANTAM PT. ANEKA TAMBANG TO FACE THE INDUSTRIAL REVOLUTION 4.0}

\begin{abstract}
This study aims to determine how to use Cyber Public Relations in social media PT. Aneka Tambang Tbk in instagram @ official.antam to faces industrial revolution 4.0. As the foundation of this study using 7-Cs PR Communications. The reseacrchers raised the sub focus researchers only take sub focus in Channel, Content, Clarity, Continuity and Consistency. The methods of this research in descriptive qualitative, the technique used in data collection is in-depth interview techniques, and observation. There were 6 informants in this study who were selected by using purposive sampling technique. To test the validity of the data the researchers used triangulation of data. The results shows the Cyber Public Relations in Social Media to faces Industrial Revolution 4.0 in instagram @ official.antam uses the Instagram channel because PT. Aneka Tambang Tbk segmentation is a young adult who uses a lot of Instagram applications. @ official.antam has contents in the form of information about the company both the products and functions of the company, commemorative holidays, CSR activities, and information about general knowledge. In Clarity PT. Aneka Tambang Tbk Instagram content has clarity in the delivery of content, PT. Aneka Tambang Tbk uses a standard language to convey the contents of the message. For Continuity and Consistency @official.antam uploads regular content every day. Instagram PT. Aneka Tambang Tbk aims to expose the company to show the essence of the company on social media, especially Instagram.
\end{abstract}

Keywords: Cyber Public Relation; Industrial Revolution 4.0; Instagram. 
Korespondensi: Ir. Lukas Sugiyanto. Sekolah Tinggi Desain InterStudi. Jln. Kapten Tendean No.2 kebayoran Baru.Jakarta 12720. No.HP. WhatsApp: 081310989949 Email: lukas@ stdi.interstudi.edu

\section{PENDAHULUAN}

Sejak kemunculannya yang pertama kali pada tahun 1969 dan tumbuh pesat pada tahun 1990an, internet memberikan kemudahan untuk mendukung pekerjaan di berbagai industri, termasuk industri komunikasi (Supranto, 2010). Tidak bisa dipungkiri perubahan bertukar informasi antar individu maupun khalayak luas berkembang sangat pesat. Dalam menjalankan fungsi komunikasi yang mewakili individu, kelompok maupun perusahaan, umumnya mengacu pada sebuah divisi yang disebut Humas atau Public Relation (Effendy, 2013). Divisi ini memegang peran penting dalam menjaga reputasi dan stabilitas organisasi. Dengan adanya penetratsi digital hal ini membuat Public Relation bertransformasi menjadi Cyber Public Relation. Solis \& Breakenridge (2010) menekankan cyber PR sebagai kegiatan berkomunikasi termasuk didalamnya memahami cara publik dalam menggunakan media online dan turut serta berinteraksi dan menyediakan informasi yang dapat membantu publiknya. Internet membuat praktisi PR dapat secara langsung terhubung dengan pelanggan. Penggunaaan Cyber Public Relation menuntut seorang PR untuk memperkaya kretifitas dalam mengemas konten yang telah direncanakan.

Cutlip, Center dan Broom dalam (Datuela, 2013) mengatakan pelaksanaan strategi PR dalam berkomunikasi dikenal dengan istilah "7-Cs PR Communications", yaitu: (1) credibility (kredibilitas), dalam hal ini komunikasi dimulai dengan suasana saling percaya yang diciptakan komunikator dengan sungguh sungguh untuk melayani publiknya yang memiliki keyakinan dan respect, (2) context (konteks), konteks yang menyangkut sesuatu yang berhubungan dengan lingkungan sosial, suatu pesan harus dapat disampaikan dengan jelas dengan sikap partisipatif, (3) content (isi), isi pesan dalam strategi ini harus menyangkut kepentingan publik, sehingga informasi dapat diterima sebagai sesuatu yang bermanfaat bagi public, (4) clarity (kejelasan), pesan disusun dengan kata-kata yang jelas, mudah dimengerti, dan memiliki maksud, tema, dan tujuan yang sama antara komunikator dan komunikan, (5) continuity and consistency (kontinuitas dan konsistensi), komunikasi dilakukan secara berulang dengan berbagai variasi pesan dan pesanpesan tersebut harus konsisten sehingga mempermudah dalam melakukan proses komunikasi untuk membujuk publiknya, dan (6) channels (saluran), pemakaian saluran yang tepat dan penggunaan media yang berbeda sesuai dengan target sasaran.

Dalam hal ini seorang PR harus memahami perbedaan dan proses penyebaran informasi secara efektif. Capability of The Audience (kapabilitas khalayak). Dengan memperhitungkan kemampuan yang dimiliki oleh khalayak, komunikasi akan efektif jika dikaitkan dengan faktor-faktor seperti kebiasaan, peningkatan kemampuan membaca, dan pengembangan pengetahuan khalayak (Ardianto, 2011).

Digitalisasi pada era industri 4.0 membawa dampak bagi korporasi sebagai bagian dari industri, baik di lingkup internal maupun eksternal. Publik dan diproyeksikan menjadi tech-savvy, dimana kemampuan 
penggunaan internet dan teknologi digital akan terus mengalami peningkatan. Proses produksi, distribusi dan konsumsi akan lebih banyak melibatkan jaringan internet dan otomasi (Darwadi, 2019).

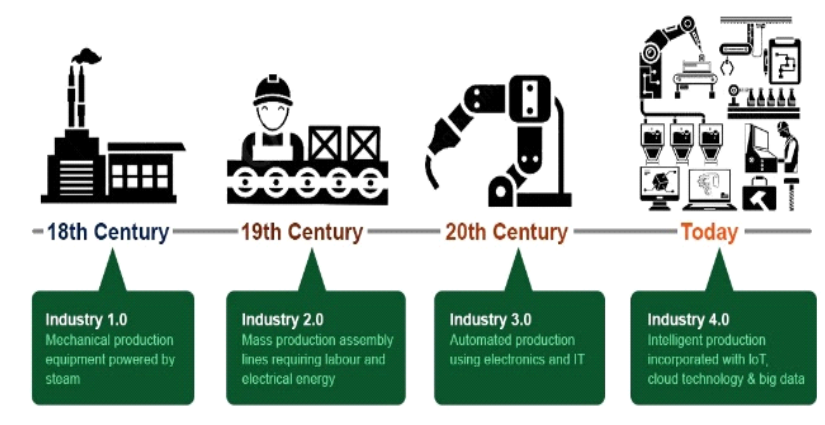

Sumber: http://medium.com/, 2019

\section{Gambar 1 Revolusi Industri}

Schwab (2016) melalui The Fourth Industrial Revolution menyatakan bahwa dunia telah mengalami empat tahapan revolusi, yaitu: (1) revolusi industri 1.0 terjadi pada abad ke 18 melalui penemuan mesin uap, sehingga memungkinkan barang dapat diproduksi secara masal, (2) revolusi industri 2.0 terjadi pada abad ke 19-20 melalui penggunaan listrik yang membuat biaya produksi menjadi murah, (3) revolusi industri 3.0 terjadi pada sekitar tahun 1970an melalui penggunaan komputerisasi, (4) revolusi industri 4.0 sendiri terjadi pada sekitar tahun 2010an melalui rekayasa intelegensia dan internet of thing sebagai tulang punggung pergerakan dan konektivitas manusia dan mesin.

Istilah Industri 4.0 secara resmi lahir di Jerman tepatnya saat diadakan Hannover Fair pada tahun 2011 (Kagermann et al., 2011). Negara Jerman memiliki kepentingan yang besar terkait hal ini karena Industri 4.0 menjadi bagian dari kebijakan rencana pembangunannya yang disebut High-Tech Strategy 2020. Kebijakan tersebut bertujuan untuk mempertahan-kan Jerman agar selalu menjadi yang terdepan dalam dunia manufaktur (Darwadi, 2019). Beberapa negara lain juga turut serta dalam mewujudkan konsep Industri 4.0 namun menggunakan istilah yang berbeda seperti Smart Factories, Industrial Internet of Things, Smart Industry, atau Advanced Manufacturing. Meski memiliki penyebutan istilah yang berbeda, semuanya memiliki tujuan yang sama yaitu untuk meningkatkan daya saing industri tiap negara dalam menghadapi pasar global yang sangat dinamis (Purwadini et al., 2018). Kondisi tersebut diakibatkan oleh pesatnya perkembangan teknologi digital dalam berbagai aspek kehidupan.

Di era teknologi digital saat ini untuk mendapatkan, menambahkan, dan menyebarkan informasi sangatlah mudah dengan kemunculan media sosial. Tentunya hal ini memudahkan Public Relation dalam menyampaikan pesannya kepada komunikannya (Yusup, 2017). Salah satu saluran informasi yang dimanfaatkan adalah internet yang tidak lepas dengan media sosial. Social media adalah media yang digunakan untuk interaksi sosial menggunakan aksesbilitas tinggi (Kaplan et al., 2010). Media sosial memiliki kekuatan besar dalam penyebaran informasi, meskipun bernaung dalam dunia maya namun media sosial memiliki kekuatan besar beberapa diantaranya untuk membentuk suatu gerakan sosial, penggalangan dana 
bahkan penyebaran isu tertentu. Sehingga dapat dikatakan media sosial kini memiliki kekuatan yang besar dalam penyebaran informasi.

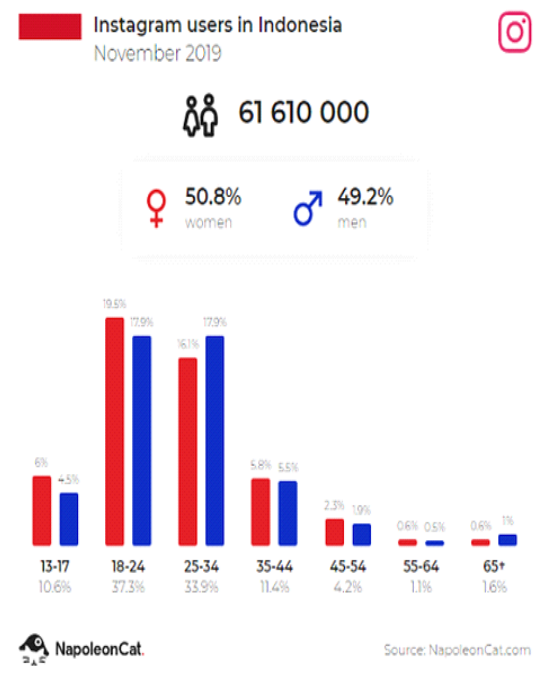

Sumber: Kompas, 2019

\section{Gambar 2 Pengguna Instagram di Indonesia}

Hingga November 2019, jumlah pengguna aktif bulanan Instagram di Indonesia dilaporkan telah mencapai 61.610.000. Setidaknya demikian menurut laporan terbaru dari NapoleonCat, salah satu perusahaan analis Sosial Media Marketing yang berbasis di Warsawa, Polandia (Sanjaya et al., 2017). Artinya, 22,6\%, atau nyaris seperempat total penduduk Indonesia, adalah pengguna Instagram. Jumlah tersebut naik tipis dari bulan sebelumnya, yang menyebut total pengguna Instagram di Indonesia mencapai 59.840.000. Pengguna Instagram dengan gender perempuan paling dominan di Indonesia. Tercatat jumlahnya mencapai 50,8\%, unggul tipis dari pengguna bergender pria yang mencapai 49,2\%. Pengguna berusia 18-24 tahun menjadi kelompok usia pengguna paling besar di Indonesia, dengan total prosentase 37,3\% atau sekitar 23 juta pengguna. Dalam rentang usia tersebut, pengguna Instagram perempuan masih dominan dengan prosentase 19,5\% dibanding laki-laki dengan presentase 17,9\%. Pengguna terbesar kedua berada di kelompok usia $25-$ 34 dengan prosentase 33,9\%. Bertolak belakang dengan kelompok usia sebelumnya, kategori usia ini justru lebih unggul pengguna pria sebesar 17,9\%, sementara pengguna perempuan 16,1\%. Sementara dari segi jumlah, pengguna pria unggul 1,1 juta. Kategori usia penggguna paling rendah adalah 65 tahun ke atas yang hanya sebesar 1,6\%. Sebagai informasi, data yang disajikan NapoleonCat ini bersumber dari API pemasaran Instagram. Salah satunya dalam dunia Public Relation yang dulu hanya dapat menyebarkan informasi secara konvensional kini seorang Public Relation dapat beralih ke dunia digital meski tidak semua pekerjaan Public Relation dapat beralih ke dunia digital (Hafni \& Renata, 2019).

\section{METODE PENELITIAN}

Paradigma yang digunakan di dalam penelitian ini adalah paradigma konstuktivis. Paradigma konstruktivis, yaitu paradigma yang hampir merupakan antitesis dari paham yang meletakkan pengamatan dan objektivitas dalam menemukan suatu realitas atau ilmu pengetahuan. Paradigma ini memandang ilmu 
sosial sebagai analisis sistematis terhadap socially meaningful action melalui pengamatan langsung dan terperinci terhadap perilaku sosial yang bersangkutan menciptakan dan memelihara atau mengelola dunia sosial mereka (Hidayat, 2013).

Pendekatan dalam penelitian ini adalah deskriptif kualitatif yang bertujuan untuk mendeskripsikan apa yang saat ini tengah berlaku. Di dalamnya terdapat upaya mendeskripsikan, mencatat, menganalisis dan menginterpretasikan kondisi- kondisi yang saat ini terjadi atau ada. Dengan kata lain, pendekatan deskriptif bertujuan memperoleh informasi-informasi tentang keadaan yang terjadi pada saat ini. Metode kualitatif merupakan prosedur penelitian yang menghasilkan data deskriptif berupa kata-kata tertulis dari para pengajar dan perilaku yang diamati untuk diarahkan kepada latar dan individu secara holistik (utuh). Penelitian dengan metode kualitatif bertujuan agar peneliti dapat mengenal dan memahami lingkungan penelitian dengan cara turun langsung ke lapangan (Mulyana, 2018).

Sumber data yang digunakan dalam penelitian ini adalah data primer melalui wawancara dengan narasumber. Serta sumber data primer melalui data yang didapatkan dari jurnal atau buku yang berkaitan dengan Cyber Public Relations di Media Sosial dalam menghadapi Revolusi Industri 4.0.

Subyek penelitian atau responden adalah orang yang diminta untuk memberikan keterangan tentang suatu fakta atau pendapat. Sebagaimana dijelaskan oleh Arikunto (2016: 145) bahwa subyek penelitian adalah subyek yang dituju untuk diteliti oleh peneliti. Subyek penelitian adalah sumber informasi yang digali untuk mengungkap data dan fakta yang terjadi di lapangan. Obyek penelitian ini adalah akun Instagram @ official.antam PT. Aneka Tambang

Tabel 1 Subyek Penelitian

\begin{tabular}{|c|c|c|c|}
\hline No. & Nama & Jabatan & Keterangan \\
\hline 1. & Arief Armanto & Public Realtion & Key Informan \\
\hline 2. & $\begin{array}{ll}\text { Andi } & \text { Tenri } \\
\text { Addeng } & \end{array}$ & $\begin{array}{l}\text { Secretary } \\
\text { Assistant } \\
\text { Manager } \\
\text { Corporate } \\
\text { Secretary }\end{array}$ & Narasumber \\
\hline 3. & Romizar & Konsumen & Narasumber \\
\hline 4. & $\begin{array}{l}\text { Nur } \\
\text { Aulia }\end{array}$ & Konsumen & Narasumber \\
\hline 5. & Ides Nur Ayanti & Konsumen & Narasumber \\
\hline 6. & $\begin{array}{ll}\text { Tania } & \text { Nur } \\
\text { Azaniyah } & \end{array}$ & Konsumen & Narasumber \\
\hline
\end{tabular}

\section{HASIL DAN PEMBAHASAN}

Media sosial instagram dipilih karena Instagram @officail.antam memiliki penggikut paling banyak diantara media sosial yang dimiliki ANTAM. Akun instagram @ antam.official sendiri telah mempunyai 83,6 ribu pengikut, yang sebagian besar masuk ke dalam kategori dewasa muda. Hal ini membuktikan bila instagram memiliki popularitas lebih di masyarakat. Informasi di instagram dapat cepat menyebar luas di masyarakat luas yang memudahkan ANTAM untuk menyasar khalayaknya serta fiturnya yang cukup efektif untuk berkomunikasi dengan khalayak seperti foto, video, sorotan, InstagramTV untuk membagikan 
informasi. Like, komen, follower, direct massage untuk mengetahui eggaggement followers Antam sebagai evaluasi di bulam berikutnya. Public Relation ANTAM editorial plan selama sebulan, menentukan target, melakukan QPA (Quality Performance Assessment) di setiap platfrom media sosial ANTAM. Berapa peningkatan followers-nya, berapa engagement-nya, harapan respon apa yang ingin didapatkan. Baru diterjemahkan kedalam konten. Dapat berupa foto atau video atau yang lainnya.

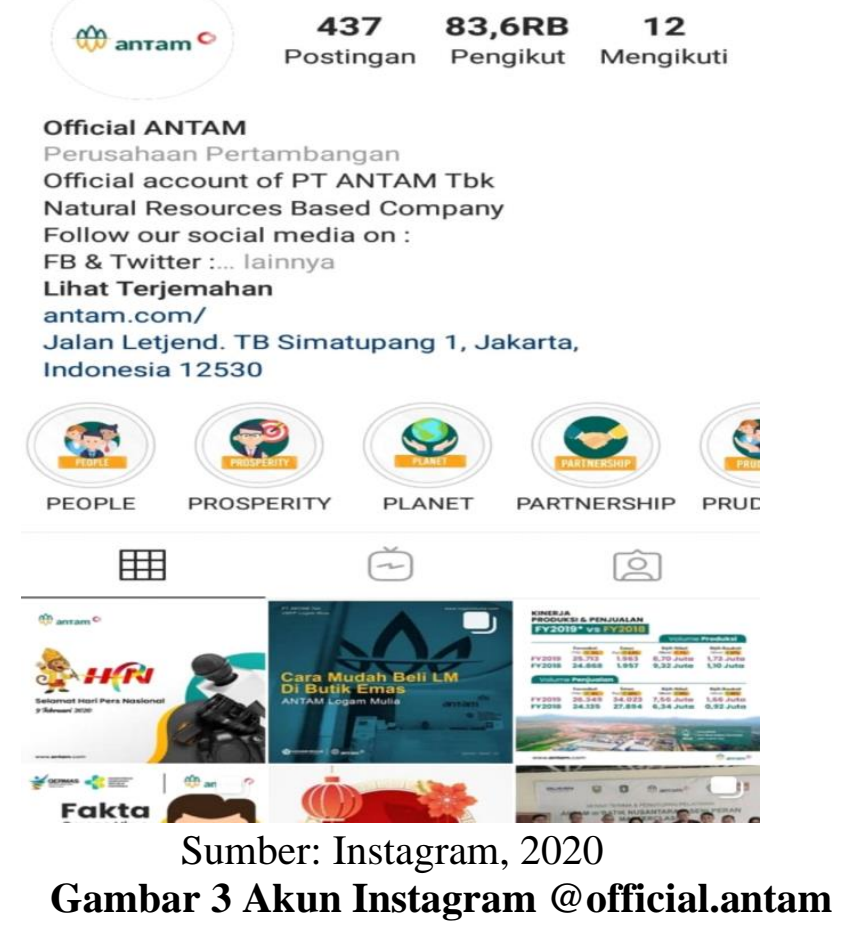

Berdasarkan teori 7-Cs PR Communications" Implementasi Cyber Public Relation pada PT Aneka Tambang di Media Sosial dalam menghadapi Revolusi Industri 4.0 dalam instagram @official.antam. Pada indikator Channel, aplikasi instagram dipilih untuk menjadi saluran komunikasi karena sasaran khalayak ANTAM sebagian besra memiliki instagram. Pengguna instagram berusia 18-24 tahun menjadi kelompok usia pengguna paling besar di Indonesia, dengan total \%tase 37,3 dan usia 25-34 dengan \%tase 33,9 \%. Dimana segmententasi khalayak Antam adalah dewasa muda pekerja yang profesional.

Selanjutnya pada indikator Content, akun @official.antam memiliki isi konten berupa foto ataupun video yang berisi informasi mengenai perusahaan baik produk maupun fungsi perusahaan, peringatan hari besar, kegiatan CSR, dan informasi seputar pengetahuan umum. Tampilan feed Antam juga dinilai cukup kreatif dan bertemakan hijau putih dan kuning sesuai logo Antam.

Ketiga, pada indikator Clarity, konten instagram @official.antam memiliki kejelasan dalam penyampaian isi konten, Pihak antam menggunakan bahasa yang baku untuk menyampaikan isi pesan. PR Antam memilih untuk menempatkan khlayaknya di Instagram sebagai khalayak profesional sehingga setiap kontennya menggunakan bahasa yang baku. 
Keempat, pada indikaror Continuity and Consistency, akun @official.antam mengunggah kontennya regulary setiap hari. Instagram PT. Aneka Tambang Tbk bertujuan untuk company expose untuk menyapa khalayaknya serta menunjukkan eksistensi perusahaan di media sosial khususnya instagram.

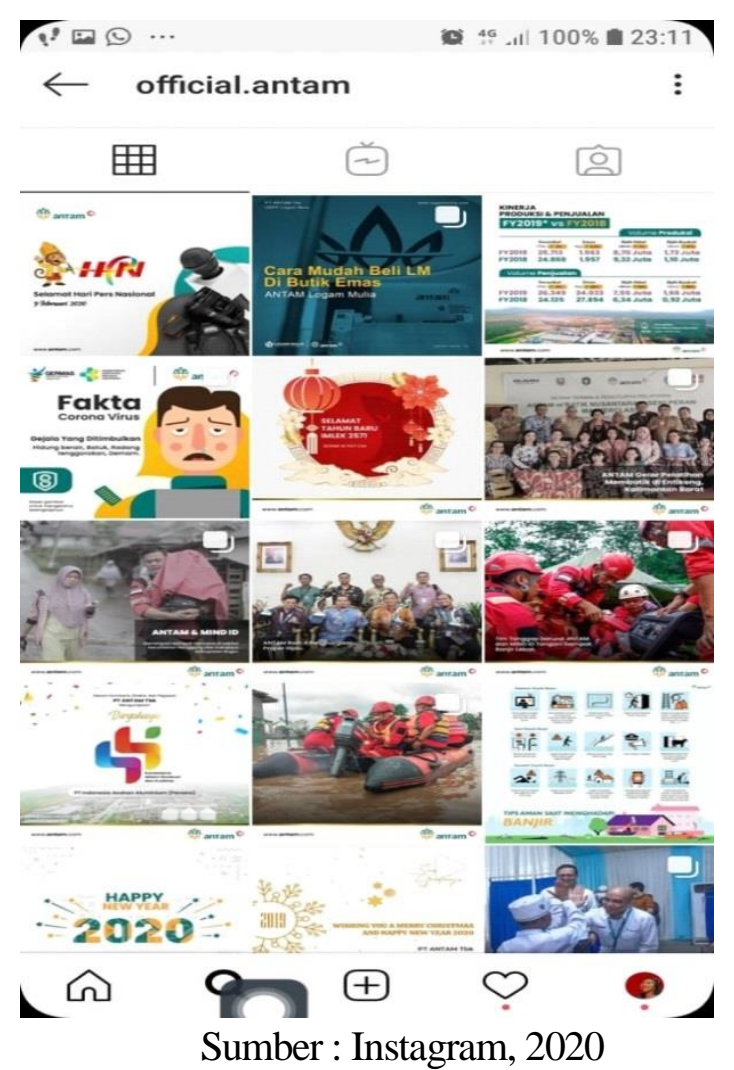

Gambar 4 Akun Instagram @ official.antam

Untuk menyesuaikan digitalisasi revolusi industri 4.0 media sosial dinilai dapat menjadi strategi dalam menghadapi revolusi industri 4.0 khususnya sebagai saluran komunikasi. Hal ini tidak dapat dipungkiri karena sebagian besar masyarakat sudah beralih ke dunia maya untuk mendapatkan informasi yang diinginkan. Karena dengan media sosial masyarakat bisa mengakses lebih luas, kapanpun dimanapun. Karena sekarang semua informasi dapat diakses media sosial.

\section{SIMPULAN}

Cyber Public Relation pada PT Aneka Tambang di Media Sosial dalam menghadapi Revolusi Industri 4.0 menggunakan instagram @official.antam dengan segmentasi khalayak dewasa muda yang banyak menggunakan aplikasi instagram sebagai Channel. Content@official.antam memiliki isi konten berupa informasi mengenai perusahaan baik produk maupun fungsi perusahaan, peringatan hari besar, kegiatan CSR, dan informasi seputar pengetahuan umum. Dalam Clarity (Kejelasan) konten instagram antam memiliki kejelasan dalam penyampaian isi konten, Pihak antam menggunakan bahasa yang baku untuk menyampaikan isi pesan. Untuk Continuity and Consistency (Keberlanjutan dan Kosistensi) @official.antam mengunggah kontennya regulary setiap hari. Instagram PT. Aneka Tambang Tbk bertujuan untuk company expose untuk menunjukkan eksistensi perusahaan di media sosial khususnya instagram. 
Berdasarkan kesimpulan yang telah dipaparkan sebelumnya penulis mencoba untuk menawarkan beberapa saran untuk pihak perusahaan, Public Relation hendaknya meningkatkan pengelolaan media sosial instagram. Karena pengelolaan instagram @antam.official yang lebih aktif akan menumbuhkan minat khalayak.

\section{DAFTAR PUSTAKA}

\section{Buku}

Ardianto, E. (2011). Handbook of Public Relation. Simbiosa Rekatama Media.

Arikunto, S. (2016). Metode Penelitian Kualitatif. Bumi Aksara.

Effendy, O. U. (2013). Ilmu Komunikasi Teori dan Praktek. Remaja Roksadakarya.

Hidayat, D. (2013). Paradigma dan Metodologi Penelitian Sosial Empirik Klasik. Departemen Ilmu Komunikasi FISIP Universitas Indonesia.

Kaplan, Andreas, M., \& Michael, H. (2010). Users of the world, unite! The challenges and opportunities of Social Media. In Businnes Horizon.

Mulyana, D. (2018). Metode Penelitian Kualitatif. Remaja Rosdakarya.

Solis, B., \& Breakenridge, D. (2010). Putting the Public Back in Public Relations. FT Press.

Supranto, J. (2010). Statistik (Teori dan Aplikasi) (VI). Erlangga.

Yusup, D. (2017). Penggunaan Cyber Public Relations Facebook Fanpage PT PINDAD (PERSERO) Kota Bandung. Universitas Komputer Indonesia.

\section{Jurnal}

Darwadi, M. . (2019). Pembentukan Citra Positif Perusahaan Melalui Cyber Public Relations. E-Jurnal Ekonomi Dan Bisnis Universitas Udayana, https://ojs.unud.ac.id/index.php/EEB/article/view/52087

Datuela, A. (2013). Strategi Public Relations PT Telkom Branch Manado dalam Mempertahankan Citra Perusahaan. Jurnal Ilmu Komunikasi Universitas Sam Ratulangi, 2, 1-15.

Hafni, F. M., \& Renata, A. (2019). Instagram @BKKBNJAWABARAT sebagai Media Komunikasi Publik. Jurnal Lingkar Studi Komunikasi Universitas Padjajaran, 5(2).

Purwadini, Dian, A., \& Irwansyah. (2018). Komunikasi Korporat Pada Era Industri 4.0. Jurnal Ilmu Sosial Universitas Indonesia, 17.

Sanjaya, A., Irwansyah, \& Alunaza, H. (2017). Pemeliharaan Hubungan dan Komunikasi Organisasi via Media Siber. Jurnal Ilmu Komunikasi Universitas Diponegoro, 14.

Schwab, K. (2016). Shaping the Fourth Industrial Revolution. 11(8).

\section{Web}

Instagram. (2020). Profil Akun Instagram @ official.antam. https://www.instagram.com/official.antam/?hl=en Kagermann, H., Lukas, W. ., \& Wahlster, W. (2011). Industrie 4.0: Mit dem Internet der Dingeauf den Weg zur 4. Industriellen Revolution. http://www.vdi-nachrichten.com

Kompas. (2019). Sebanyak Inikah Jumlah Pengguna Instagram di Indonesia? https://tekno.kompas.com/read/2019/12/23/14020057/sebanyak-inikah-jumlah-pengguna-instagram-diindonesia 